\title{
Konstantinos N. Deligiorgis
}

\section{Herodotova »amazonska« Artemizija}

\section{ARTEMIZIJA V HERODOTOVIH ZGODBAH}

Skrivnostna Artemizija je ena izmed tistih žensk, ki dosegajo moške standarde, čeprav ni mogoče dvomiti o njihovem spolu, značaju in posebnostih. Najdemo jo v zadnjih knjigah Herodotovih Zgodb, kjer s svojo dinamično in hkrati svarilno vlogo na svoj način "namiguje«, da je človeška moč omejena in da, kadar jo skušaš preseči, prikličeš katastrofo. Kot kraljica ${ }^{1}$ Halikarnasa, Herodotovega rodnega mesta, ${ }^{2}$ je sodelovala pri Kserksovem ambicioznem pohodu na Grčijo. To dejstvo odpravlja vsak dvom glede podatkov o njenem življenju; skupno poreklo nedvomno zagotavlja neposrednost in veljavnost zgodovinarjevih virov, poleg tega pa mu omogoča, da opisuje ključne trenutke njenega delovanja in pri tem oriše njen značaj z mešanico izvirnosti in - zakaj pa ne? - pretiravanja.

Kot se zdi, je Artemizija v nekem čudnem smislu "prostovoljno hrabra«; razen tega, da je del mogočne vojske, v kateri so celo poveljniki sužnji, prisiljeni služiti velikemu perzijskemu kralju, premore - iz nebistvenih razlogov - neko vrsto svobode, ${ }^{3}$ in po tem se jasno razlikuje od drugih. Ta svoboda, nenavadna za Kserksovo zaveznico, združena z izrednim junaštvom, neskladnim z njeno žensko naravo, naredi iz nje simbol in hkrati enigmo ter jo uvršča v ozki nabor osebnosti, ki so pritegnile takšno zanimanje in pozornost zgodovinarjev, da so jih poimenovali »čudeži« $(\theta \dot{\omega} \mu \alpha \tau \alpha){ }^{4}$

Poleg tega številna protislovja v pripovedi o tej zgodbi naredijo ta »čudež»

1 Pravzaprav je večina velikih in uspešnih žensk v antiki del aristokracije in njihovo delovanje je pogosto povezano z mogočnim moškim. Glej tudi Lefkowitz, Heroines and Hysterics, 61.

2 Morda je bil Herodot ponosen na dosežke svoje rojakinje, čeprav je imel tudi dober razlog za nenaklonjenost njeni družini - spomnimo se, da je bila kraljica Karije stara mati tirana Ligdamisa. Ligdamis je Herodota izgnal na Samos, toda kasneje je uspel pri izgonu tirana iz Halikarnasa.

Glej Romm, Herodotus, 50.

3 Glej Munson, Telling Wonders, 257.

4 Glej Munson, »Artemisia in Herodotus«, 94-95. 
še bolj izjemen. Ko Herodot opisuje priprave na bojni pohod, poimensko navede le nekaj izbranih poveljnikov ${ }^{5}$ Kserksove ogromne vojske, vendar posebej omeni Artemizijo. Artemizija je značilna in dragocena izjema v zgodovinarjevi selektivnosti; čeprav se bojnega pohoda udeleži samo s petimi ladjami, ji posveti najobširnejši del zgodovinske naracije, kar zadeva perzijsko stran, če izvzamemo poveljnika Mardonija. ${ }^{6}$ Kot mati bi lahko v miru skrbela za svojega otroka v razkošju in varnosti kraljevske palače, ${ }^{7}$ vendar se odloči, da bo tvegala življenje daleč stran od nje. Čeprav spada v perzijski tabor ambicioznih osvajalcev, se hkrati pojavlja kot poveljnica Grkov, ki jih vodi proti drugim Grkom. ${ }^{8}$ Kako naj si torej pojasnimo to nenavadno dejstvo?

Odgovor se najbrž skriva v njenem značaju. Zdi se, da ima Artemizija lastnosti, ki se ujemajo z lastnostmi Perzijcev, vendar so jim hkrati nasprotne, in ta »spremenljivost « vpliva na njen odnos z grškimi nasprotniki. Kot azijska vladarka - zavojevalka, ki na koncu postane skrbnica Kserksovih otrok, se identificira $\mathrm{z}$ aristokracijo barbarov. Pred očmi presenečenih Grkov se prikaže kot utelešenje »narobe sveta«, v katerem ženske postanejo moški.

Ta nekompatibilna, »moška« plat njenega značaja je v Herodotovem portretu Artemizije prevladujoča; in gotovo je, da se Herodot, če bi poznal kakršnekoli "pikantne« ženske podrobnosti - kot na primer vroče zgodbe o zapeljevanju, strasti ali celo ljubezenskem maščevanju - ne bi pomišljal, da jih razkrije. Vendar se njegova Artemizija izogiba izrabljanju spolnosti in drugih »neprimernih « metod, da bi dosegla svoje cilje. Poleg tega s tem, da poudarja svojo nadarjenost tako na teoretično-svetovalni ${ }^{9}$ ravni kot na bojnem polju, predstavlja pristni »moški« grški svet.

Po podrobnostih o pripravah na pohod bomo Artemizijo ponovno srečali v osmi knjigi Zgodb, v Faleru. Pred pomorsko bitko pri Salamini je Kserks sklical pomemben posvet, da bi sprejeli ključno odločitev. Kot monarh komunicira s svojimi svetovalci samo posredno, po zaupniku Mardoniju, svetovalci pa so hierarhično razporejeni po svojih mestih. Kserks hoče slišati mnenje večine svojih zaveznikov o vprašanju, ali naj se odvije odločilna pomorska bitka pri Salamini ali ne, in vsi mu nemudoma odgovorijo pritrdilno. ${ }^{10}$

Predvsem je nenavadno, da čeprav na perzijski posvet nepričakovano »vdre« slutnja demokracije-svobode govora, to samo razgali različne motivacije govorcev in, končno, upraviči strogi despotizem. Na eni strani

5 Po Herodotu ni potrebno navajati zavezniških poveljnikov, saj so se vsi udeležili pohoda neprostovoljno, kot sužnji. Glej tudi Benardete, Herodotean Inquiries, 192-193.

6 Glej Munson, "Artemisia in Herodotus", 92.

7 Glede tega aspekta Artemizije glej How in Wells, A Commentary on Herodotus «, 586.

8 Velik vtis naredi dejstvo, da so se celo Atenčani počutili osramočene zaradi drznosti barbarske ženske, pripravljene, da se bori proti Grčiji. Tako so obljubili veliko nagrado vsakomur, ki bi mu jo uspelo ujeti. Glej tudi Bowie, Herodotus: Histories Book VIII, 158, in Pomeroy, Godesses, Whores, Wives, 100.

9 Artemizija je »dala kralju najboljši nasvet« (7.99.3). Izkaže se za odlično svetovalko; njene vojaške veščine gredo $\mathrm{z}$ ramo ob rami $\mathrm{z}$ njeno strateško sposobnostjo.

10 O kratkosti govorov večine na zasedanju glej Konstantakos, »The Warlike and the Wary«, 221. 
so govorci, ki se, ko nagovarjajo Kserksa, zavedajo, da je tako ali tako njihov monarh, tako da bo končna odločitev odvisna od njegove presoje. Njihov glas očitno izvira iz strahu pred možnim nezadovoljstvom oblastnika in jezo, ki bi ga spremljala, ne pa iz jasnega in strateškega premisleka, ki naj bi utemeljil pravilnost kakršnega koli predloga; v resnici vsi izražajo in odmevajo to, kar bo ugajalo Gospodarju. ${ }^{11}$

Na drugi strani vidimo Artemizijo, ki je ne zadevajo običajni stereotipi o barbarih. Čeprav spoštuje in sprejema vladarjevo despotsko okolje, njene vloge modre svetovalke ne določa pritisk, ki ga perzijski sistem vladanja narekuje ostalim svetovalcem in dvorjanom. Nasprotno, kot se zdi, uživa izjemni privilegij, da presega vnaprej določena pravila »odnosa « med gospodarjem in sužnjem, ko prostovoljno sodeluje pri obsežni odpravi. Kraljica bo obranila svojo pravico do tega, da pove resnico, in njena drža izraža pogum brez primere, čeprav tvega celo glavo.

Njenim besedam daje še večjo težo to, da se je odlikovala med predhodnim pomorskim spopadom pri rtu Artemiziju. Pogumno se opredeli proti bojevanju na morju in poudarja, kako nevarna je pomorska bitka, saj so Grki vešči pomorščaki. Sicer pa so, kot pravi, glavni cilj odprave - uničenje Aten že dosegli.

Močnemu nasprotovanju na posvetu sledi Artemizijin predlog, ki poudarja njeno strateško nadarjenost, čeprav ga slednjič ne bodo upoštevali:

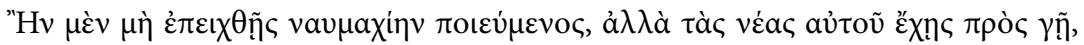

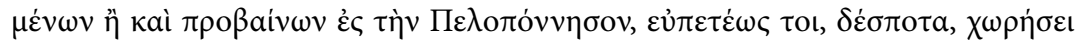

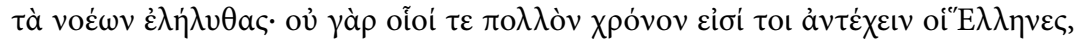

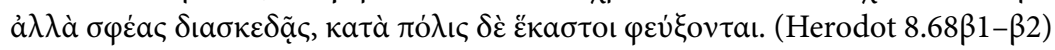

Če se ne boš dal zavesti v bitko, ampak ostaneš z brodovjem tu ob kopnini, ali če odjadraš dalje na Peloponez, se ti bo vse samo od sebe izteklo po želji. Zakaj Grki nasproti tebi ne morejo dolgo zdržati, razkropil jih boš, in vsak bo gledal, da pride domov. $^{12}$

Predlaga, naj napadejo Peloponez, da bi uničili grško zvezo in prisilili njene člane, da si poiščejo zavetje vsak v svoji domovini. Dejansko so bili grški zavezniki, ki jih je pograbila panika, pred Temistoklejevim odločnim posegom že tik pred tem, da bi naredili nekaj podobnega; ko so Grki slišali za obleganje in padec Akropole, so se pri priči hoteli za vsako ceno izogniti spopadu pri bližnji Salamini! Kdor bi pričakoval, da je takšen smiseln predlog prišel od

11 Cel potek kaže, kako despotizem uniči sposobnost ljudstva, da bi sodelovalo pri političnih odločitvah. Seveda je Kserks povsem odgovoren za pogubno odločitev glede odločilnega spopada pri Salamini. Če bi hotel, bi se zlahka odločil drugače, kot mu je svetovala večina svetnikov. Vendar se Herodot osredotoča predvsem na suženjskost in uslužnost večine Kserksovih podložnikov. Glej tudi Munson, »Artemisia in Herodotus«, 96.

12 Vsi odlomki iz Herodota so navedeni po: Herodot iz Halikarnasa, Zgodbe, prev. Antone Sovrè (Slovenska matica: Ljubljana, 2003); op. prev. 
izkušenega generala, bo povsem razočaran; Herodot oblikuje svojo Artemizijo $\mathrm{v}$ posebno in možato osebnost in na to ne pozabi ob nobeni priložnosti.

Poleg tega se zdi, da kraljico res skrbi, kaj bi se zgodilo, če bi se Kserks odločil odobriti nenadni napad - potencialno uničenje pehote bi lahko bilo

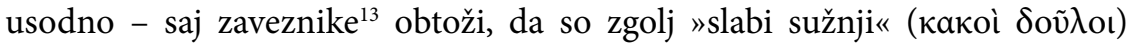
nadarjenega voditelja. Artemizija zaključi svoj govor skoraj enako, kot ga je začela, s podcenjevanjem sestave in zmožnosti perzijske vojske. S tem opozori, da imajo Grki premoč zaradi boljše vojaške pripravljenosti, in jasno je, da je pogum te »moške« junakinje vreden občudovanja.

Njena odkritosrčnost je poslušalce presenetila in po njenem govoru so se ti, ki so ji bili naklonjeni, bali, da bo kaznovana za svarilni zgled; njim nasproti pa so stali tisti, ki so verjetno imeli veliko razlogov, da so ji zavidali:

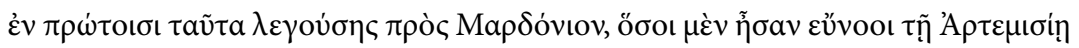

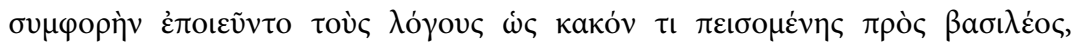

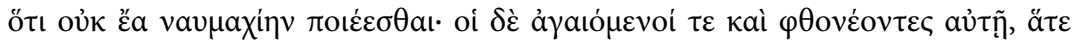

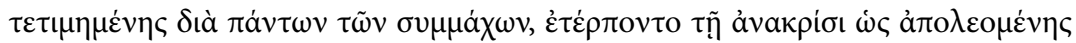
aủंñ (Herodot 8.69.1)

Artemisiinim prijateljem je bilo žal njenega odgovora Mardoniu, ker so se bali, da ji bo kralj zameril, da mu odsvetuje bitko; nasprotniki in zavistneži pa, ki so ji bili nevoščljivi, ker jo je odlikoval pred vsemi drugimi zavezniki, so se veselo muzali, saj so bili uverjeni, da bo zbog svojega mnenja prišla $\mathrm{v}$ nemilost.

Toda njihova pričakovanja se niso izpolnila, saj se Kserks ni pomišljal pohvaliti njenega nasveta.

Na koncu je kralj zavrgel Artemizijin načrt, ki bi verjetno lahko Perzijcem brez resnejših izgub prinesel zmagoslavje. ${ }^{14}$ Kot se rado zgodi v življenju, eni napaki sledi naslednja, nadvse tragična; za Perzijce je ta "moto« pomenil poraz pri Salamini. V nekem smislu je ironično, da Kserks sledi predlogu večine, čeprav so ti prej iz strahu pred njegovo močjo privzeli njegovo lastno mnenje! ${ }^{15}$ Hkrati omeni nekaj, kar »osvetli« njegovo avtoriteto despota $\mathrm{z}$ druge plati: prizna, da se njegovi vojščaki v nekaterih izmed prejšnjih bitk niso borili hrabro, vendar meni, da se bodo tokrat obnašali drugače, saj bo osebno navzoč, pa čeprav od daleč.

Artemizija se ponovno pojavi med spopadom na morju pri Salamini. Herodot, ki ga ne zanima opisovanje posamičnih ključnih momentov pomorske bitke, naenkrat sklene, da bo izjemoma omenil dogodek, ki bo kmalu še povečal Kserksovo občudovanje Artemizije. Toda zgodovinar nas v

13 Artemizija kot primer omeni Ciprčane, Kilikijce in Pamfilijce (8.68c.1), čeprav ti niso bili podložni Perzijcem. Glej Bowie, Herodotus: Histories Book VIII, 159.

14 Glej Flower, »Herodotus and Persia«, 286.

15 Glej tudi 7.8.1, kjer Kserks namerava zbrati perzijske aristokrate in sklicati posvet o kaznovanju Aten, vendar se je hkrati že sam odločil, ne da bi zares pričakoval njihovo mnenje. 
nekem smislu »zavaja« - kot nas bo v kratkem tudi Artemizija - ko se izkaže, da je na videz junaško dejanje sad izdaje. ${ }^{16}$

Med splošno paniko in zmedo je Artemizija, ko je atiška trirema preganjala njeno ladjo, da bi jo potopila, izvedla manever:

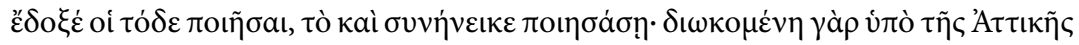

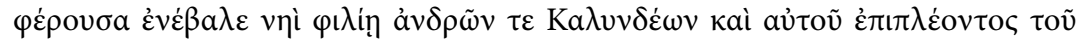

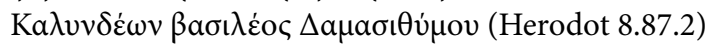

Pomagala [si je] po svoje in manever se ji je posrečil: vtem ko ji je Atenec sledil tik za petami, se je z vso silo zaletela v prijateljsko ladjo kalindiško, na kateri je bil sam kralj Kalindijcev, Damasitimos.

Ni dvoma, da je tako ravnala nalašč. Toda kakšen razlog za to bi lahko imela? Je šlo le za nujno rešitev v usodnem trenutku? Ali pa je med poveljnikoma obstajalo staro rivalstvo, ki se je zdaj tragično razrešilo? ${ }^{17}$

Herodot pravi, da ni mogoče vedeti, ali sta se Artemizija in Damasitim že sporekla kdaj prej na Helespontu. Zdi se, da je to eden redkih primerov, ko Artemizija ravna pristno zvijačno in uspe na več ravneh. Po eni strani se ji posreči zavesti atensko triremo, katere posadka je gotovo domnevala, da je ladja grška, ali vsaj, da je prebegnila iz perzijske mornarice. ${ }^{18}$ Po drugi strani ob tem, da si reši življenje, tudi zmede Kserksa, ki s svojega oddaljenega položaja ni mogel z gotovostjo razbrati oznak potapljajoče se ladje. Zaradi tega je Kserks verjel besedam perzijskih častnikov ob sebi in je na koncu Artemizijo še pohvalil! ${ }^{19}$ Seveda ne pozabimo, da je imela kraljica Karije veliko sreče, saj se ni nihče z Damasitimove ladje rešil iz morja, da bi jo lahko obdolžil izdaje.

Na tem mestu je vredno dodati še drug aspekt: ironični zagovor prevare iz Kserksovih ust bi nas v povezavi s predhodnimi dogodki na perzijskem zboru v Faleru lahko napotil k drugačnemu pogledu na to Artemizijino potezo. Ko je Artemiziji - kljub prizadevanju - spodletelo, da bi prispevala k skupnemu dobremu, se je oddaljila od preostalih zaveznikov. Osamljena na sovražnih morskih vodovjih, $\mathrm{z}$ občutkom, da je odtujena od ostalih Kserksovih svetovalcev, je začela gledati na lastno korist, pa čeprav za ceno nedolžnih življenj zaveznikov! $\mathrm{Z}$ ozirom na to je njena poteza nekonvencionalna, "pomešana « $\mathrm{Z}$ agresijo in izdajo ter moralno nesprejemljiva. ${ }^{20}$

Seveda iz tega ne smemo sklepati, da hoče Herodot »spodkopati« ugled junakinje iz svojega rodnega mesta; samoumevno je, da občuduje nadarjeni

16 Glej Hazewindus, When Women Interfere, 29.

17 Damasitim, kralj Kalindijcev, je sodil med najvidnejše poveljnike perzijskega ladjevja. Glej tudi Bowie, Herodotus: Book VIII, 178.

18 Glej Dewald, „Women and Culture in Herodotus' Histories«, 109.

19 Glej Munson, Telling Wonders, 256. Brez dvoma je bil Kserkses zaveden, da ni prepoznal identitete potopljene ladje. Ženska na videz ravna junaško, zato da ne bi tvegala življenja, temveč zbežala in preživela.

20 Glej Munson, »Artemisia in Herodotus«, 105. 
in prebrisani Artemizijin značaj. Bila je zmožna pravilno oceniti težo trenutka in vedno je znala uporabiti najprimernejše orožje, da je premagala nevarnosti, se izognila pastem in na koncu odnesla celo kožo. Katastrofa pri Salamini je mnogim Perzijcem prinesla pogubo. Panika ogromnega ladjevja, ki se umika in izgublja bitko, pa se ni dotaknila inteligentne poveljnice, ki je našla rešitev v domislekih lastnega uma namesto v svoji pomorski veščini.

$\mathrm{V}$ zadnjem prikazu Artemizije v Herodotovi naraciji jo spet najdemo $\mathrm{v}$ Kserksovi bližini in ta ponovno potrebuje njen nasvet. Kralj na kratko povzame besede, ki jih je prej izrekel Mardonij: mora se odločiti, ali naj ostane v Grčiji in napade Peloponez ali pa naj se vrne v Azijo in v Grčiji pusti svojega namestnika ter veliko vojsko tristo tisočih pešakov in konjenikov. Ker se je kraljica na posvetu v Faleru izkazala za edino modro svetovalko, ima kralj dober razlog, da ji ponovno zaupa, zato jo spet prosi za pomoč.

Artemizija kralju polaska, ko pokaže, da ji je ljubša previdnejša alternativa, ${ }^{21}$ in prizna, da ji je Kserksova varnost vedno prednostna skrb. Poleg tega je bilo veliko bolj gotovo in varno zagovarjati kraljev odhod, saj je v Grčiji osebno tvegal. Celo v nezaželenem scenariju Mardonijevega poraza ali smrti ugled in življenje Kserksa ne bi bila izpostavljena nevarnosti.

Končno kraljica zavrne možni ugovor, da ambiciozni bojni pohod ni izpolnil zastavljenega cilja, in zatrdi, da so Atene že uničene. Kserks bi gotovo hotel požeti več uspehov, toda v tem trenutku Artemizija bolj ko ne namiguje, da je bil požig v Atenah enak temu v Sardah med predhodno jonsko revolucijo! ${ }^{22}$ Govor je tolažilen, vendar se oddaljuje od vsake zgodovinske realnosti in je v resnici le poskus, da bi prikrila perzijski polom. Tokrat Kserks prisluhne Artemizijinemu nasvetu, ${ }^{23}$ in avtor ne spregleda njegovega lastnega strahu.

Če je na Salamini pohvala mogočnega kralja dejansko posledica razdalje, ki ga je ločevala od bojnega polja, se v tem primeru ne zgodi nič podobnega. Poleg tega, da jo ponovno pohvali, Kserks Artemizijo zaprosi, naj pospremi njegove nezakonske otroke $\mathrm{v}$ Efez. ${ }^{24}$ Njena navzočnost $\mathrm{v}$ Herodotovih Zgodbah se tu končuje enako impresivno, kot se je začela: kraljica Karije, ki se je prostovoljno udeležila velikega podviga, sicer $\mathrm{z}$ majhnim številom ladij, vendar z veliko, "moško" samozavestjo, se odpravlja na pot domov, ne da bi izgubila svojo prodornost in odličnost, pri čemer jo spremlja blagoslov velikega monarha.

Ob tem lahko dobimo občutek, da se nekaterim redkim ljudem, nekakšni

21 Glej Konstantakos, »The Warlike and the Wary«, 228.

22 Požig Aten je bil že prej omenjan kot glavni Kserksov cilj (7.8b.2). Glej tudi Chiasson, »Tragic Diction in Herodotus «, 158, in Bowie, Herodotus: Histories Book VIII, 192.

$23 \mathrm{~V}$ nasprotju s posvetom v Faleru se tukaj ne pojavijo različna mnenja. Kralj se odloči za intenziven pogovor s svojo svetovalko in lahko bi opazovali le »etični konflikt značajev« med grobim Mardonijem ter modro in previdno Artemizijo. Za več detajlov glej Masaracchia, Erodoto. La battablia di Salamina, 208.

24 V Efezu se je začenjala cesta do Sard, ki je peljala do velike državne poti v perzijsko prestolnico, Suzo. 
eliti, življenje samo smehlja: če sodimo po življenjski poti te ženske, je očitno prejela veliko nasmehov: na rtu Artemiziju se je izkazala njena hrabrost, v Faleru sta bili pohvaljeni njena tvegana poteza in drznost, pri Salamini je rešila sebe in svoje rojake s svojo "pozabljeno «zvijačnostjo. Če je Artemiziji kaj spodletelo, potem samo to, da ji ni uspelo prepričati prave osebe v pravem trenutku. Kako zelo drugače bi potekale stvari, če bi se ji to posrečilo? Odgovor nam bo vedno pustil grenak priokus, saj morda intuicija ali napoved zla ni blagoslov, ampak prekletstvo.

\section{AMAZONKE: POSKUS PRIBLIŽANJA CIVILIZACIJI}

Nekaj piscev iz petega stoletja je razvilo celo etnografsko književnost o legendarnih likih Amazonk. Te naracije so pogosto prikazovale njihov "svet « kot sistematično subverziven v odnosu do grške kulture in včasih kot alternativni kulturni predlog. Herodot tako med pripovedovanjem o Darijevem pohodu proti Skitom omenja tudi navade ljudstev s tega območja. ${ }^{25}$ Nekaj strani posveti zgodovini Amazonk, ki naj bi ponujala razlago za čudne navade Sarmatk; ženske iz tega oddaljenega skitskega plemena imajo zelo rade tako lov kot ježo, oblačijo se v moške obleke in se pogumno udeležujejo bitk. ${ }^{26}$

Amazonke so, drugače kot druga plemena, ki jih omenja Herodot, izumrl rod; ${ }^{27}$ globoko so zakoreninjene v mitološkem izročilu, njihova vloga pa je edinstvena in osrednja: vloga premaganih, podvrženih ali ujetih. Amazonke so bile divje in nepokorne, vodila jih je nenasitna želja po dominaciji. Kot takšne so predstavljale resno grožnjo človeštvu in nekdo, junak, ${ }^{28}$ se je moral z njimi spopasti in jih ukrotiti.

Herodot pa se ogradi od dobro poznanih mitskih modelov; v nekem smislu je ustvaril Amazonke kot zgodovinske in ne mitske like ${ }^{29}$ - očitno nenavadne, vendar ne povsem tuje navadam drugih ljudstev. V četrti knjigi svojega dela se zgodovinar osredotoči na Sarmate, pleme, ki je izviralo iz zveze med Skiti in Amazonkami. ${ }^{30}$ Skupina Amazonk je preživela poraz na reki Termodon in Grki so jih zajeli (4.110.1). Ko so jih odvažali na treh različnih ladjah, so Amazonke zaklale stražarje in pobegnile na prostost. Ker pa se niso niti najmanj spoznale na plovbo, ${ }^{31}$ jih je odnesel tok in so prispele na obale

25 Glej Flory, The Archaic Smile of Herodotus, 108.

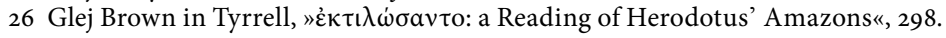

27 O njihovem izginotju potem, ko so jih Atenčani premagali, glej Lys., Epit. 4-6. Spodleteli vdor Amazonk v Atiko je na neki način napovedoval spodleteli napad Perzijcev na Atene in Grčijo nasploh. Glej tudi Lefkowitz, Heroines and Hysterics, 8, in Vandiver, Heroes in Herodotus, 65.

$28 \mathrm{Za}$ več podrobnosti o spopadih med Amazonkami in najbolj znanimi grškimi junaki glej Munson, Telling Wonders, 124.

29 Glej Hazewindus, When Women Interfere, 211. Za nasprotno stališče glej Tyrrell, Amazons, 2425, Rostovzeff, Iranians and Greeks in South Russia, 33.

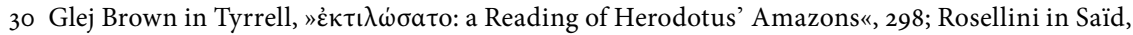
»Usage de Femmes et autres Nomoi«, 998.

$31 \mathrm{O}$ očitnem pomanjkanju pomorskih veščin pri Amazonkah tudi Hartog, The Mirror of 
Majetijskega jezera ter se začele preživljati z ropanjem:

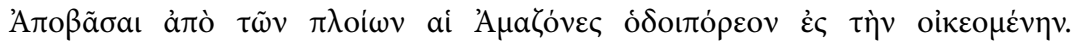

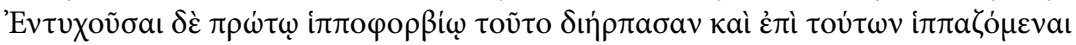

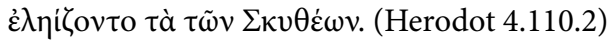

Tu so se Amazonke izkrcale in se klatile po okolici. Ugrabile so prvo čredo konj, ki so naletele nanjo, se okonjile in ropale po skitski pokrajini.

Lokalno prebivalstvo je običajno branilo svojo zemljo pred neznanimi bojevniki. Vendar so na Amazonkah opazili nekaj čudnega, čeprav niso mogli verjeti, da se $\mathrm{v}$ resnici ne borijo $\mathrm{z}$ mladimi moškimi. Ko so prebivalci ugotovili - potem ko so pobrali trupla ubitih Amazonk - da so ženske, ${ }^{32}$ so se zavedeli, da razlika v spolu narekuje dopolnjevanje, in ne konflikta. Potem so k njim poslali skupino mladih Skitov, ki so jim naročili, naj posnemajo, karkoli počnejo te čudaške ženske, ${ }^{33}$ da bi jih tako bolje spoznali in kasneje z njimi imeli otroke. Nekega dne je obema skupinama, ko sta dosegli in prešli meje nekakšnega »bratstva «, ${ }^{34}$ uspelo zaživeti skupaj v neki obliki sobivanja brez stereotipov in neenakosti konvencionalnega tradicionalnega zakona. ${ }^{35}$

Tako se zgodba ne konča krvavo, ne pojavi se slutnja moške agresije, zgolj »strategija « približanja ženskam. ${ }^{36}$ Sprva Amazonke »sprejemajo « ženskost na ravni spolnosti in to postopoma pripelje do neke vrste »ukrotitve«: zdaj so poročene ženske, ki so sprejele in uvedle novo obliko življenja. Jih sploh še lahko povezujemo s tistimi "možatimi« nasilnimi ženskami, ki so poklale grške stražarje in živele onkraj zakona? »Ukrotitev« Amazonk ne postavlja $\mathrm{v}$ sekundarno vrednostno polje; nasprotno, kot udeleženke v novem skupnem okolju obdržijo visoko stopnjo avtonomije. $\mathrm{V}$ dveh primerih celo prevzamejo pobudo, na kar njihovi mladi možje nemudoma pristanejo. To nasprotuje tradicionalnim zakonom patriarhata, ki so utemeljeni na prevladi moškega nad žensko, moža nad ženo. Mladi Skiti najprej sprejmejo predlog, da se razdeli njihovo ozemlje, da bi živeli skupaj z Amazonkami. Kmalu zatem pristanejo na drugi predlog in se vsi skupaj preselijo na precej osamljen kraj.

Herodotus, 224, in Blok, The Early Amazons, 87.

32 Razkritje prave identitete Amazonk prekine agresivno razpoloženje na obeh straneh. Glej tudi Hazewindus, When Women Interfere, 214-215.

33 Očitni odgovor na vprašanje, ki bi si ga morda lahko zastavili, zakaj so bili samo mladi Skiti izbrani, da se približajo Amazonkam, je, da so takšno »misijo «lahko izvedli samo mladeniči, ker so bili odrasli Skiti običajno poročeni. Poleg tega je bil način življenja Amazonk, ki je temeljil na lovu in ropanju, primeren predvsem za mlade in ne toliko za zrele moške. Tako so se odločili, da jih bodo nalašč oponašali, se pravi, da bodo uporabili zvijačen pristop, in takšen odnos je pogosto primeren za najstnike in njihovo mentaliteto.

34 Glej Flory, The Archaic Smile of Herodotus, 108.

35 Potem ko Amazonke sprejmejo spolnost in materinstvo, igrajo novo vlogo, toda ne pristanejo na to, da bi postale tradicionalne žene, kot so morda pričakovali Skiti.

36 Glej Hazewindus, When Women Interfere, 193. 
Rekel bi, da se Skiti po vsem sodeč ne zavedajo, kako se vsakič, ko ubogajo svoje žene, vse bolj oddaljujejo od korenin, tradicije in na koncu od dežele same. Zdi se, da Amazonke v takšnih zakonih igrajo dominantno vlogo, celo če pri tem izgubijo lastni jezik, saj se ga njihovi možje niso mogli naučiti. $\mathrm{V}$ bistvu bodo skupaj osnovali idealno skupnost, v kateri je število žensk in moških enako. Poleg tega v njej ni starcev, ki bi zahtevali skrb in nego, niti potrebe po doti za ženske. ${ }^{37}$

Sicer pa drugi predlog Amazonk izvira iz bojazni, da se jim tasti ne bi maščevali za njihovo naporno obnašanje. Ta bojazen kaže na stopitev s svetom, drugačnim od njihove preteklosti: niso bile več grobe, nekakšne nadnaravne "pošasti«, ki so sejale bojazen; niso več niti ignorirale zakona niti sovražile moških. ${ }^{38}$ So aktivni del nove skupnosti, »muči« jih grešna preteklost, vendar lahko upajo na svetlo prihodnost.

Toda če se vrnemo k Herodotovi naraciji, je jasno, da se Sarmatke obnašajo "po amazonsko«: jezdijo in lovijo, oblečene so v moška oblačila in spopadajo se v vojnah. Nekako so »ujete« med možatostjo in ženskostjo, saj igrajo vloge in prevzemajo naloge, ki pripadajo obema spoloma, živijo pa v deželi daleč proč od civilizacije. ${ }^{39}$ Poleg tega čuden in krut "zakon« ni dopuščal, da bi se dekle poročilo, preden ne ubije vsaj enega sovražnika! Na žalost je to čudaštvo nekatere Sarmatke obsodilo na to, da umrejo neporočene: ${ }^{40}$

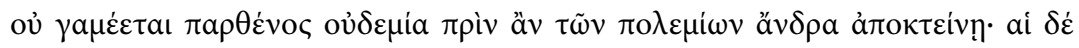

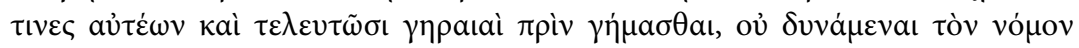
$\dot{\varepsilon} \kappa \pi \lambda \tilde{\eta} \sigma a ı$ (Herodot 4.117)

Pri njih se ne omoži nobeno dekle, preden ni ubila sovražnega moža, in mnoge ostanejo vse življenje stare device, ker ne morejo ustreči običaju.

To nas lahko navede na misel, da poroka ni bila samoumevna kot nekakšen privilegij in da je bila popolna vključitev žensk v družbo odvisna od njihovega primarnega prispevka vojščakinj, in ne žena. Ni se razlikovalo med moškimi in ženskimi opravili, ni bilo nasprotja med vojskovanjem in poroko, saj se slednja sklene šele po udeležbi v boju. ${ }^{41} \mathrm{~V}$ takšnih okoliščinah je Sarmatkam uspelo ohraniti njihovo tradicionalno »amazonsko« istovetnost, čeprav so zanjo nekatere morale plačati ogromno ceno: svojo žensko izpolnitev.

37 Glej Flory, The Archaic Smile of Herodotus, 112.

38 Glej Munson, Telling Wonders, 132.

39 Takšen način življenja v bistvu opozarja na položaj ženske v nomadskih plemenih. Glej tudi

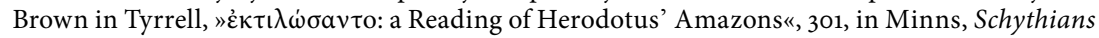
and Greeks, 84 .

40 Očitno je, da o Sarmatkini bodočnosti in usodi odloča ta kruti "zakon « namesto njene domnevne skrite želje, da bi se poročila. Glej tudi Blok, The Early Amazons, 88, Hazewindus, When Women Interfere, 211.

41 Glej Rosellini in Saïd, "Usage de Femmes et autre Nomoi«, 998, in Blundell, Women in Ancient Greece, 60 . 


\section{"AMAZONSKA"ARTEMIZIJA}

Če se zdaj vrnemo k Artemiziji, se lahko vprašamo, kako zelo »amazonska» je navsezadnje ta posebna junakinja. Resnica je, da vsebuje značaj Herodotove rojakinje poteze, ki jo ločujejo od Amazonk, toda tudi povezujejo z njimi; na primer, enako agresivna je, pripravljena se je boriti in prostovoljno sodelovati pri bojnem pohodu, ne da bi jo k temu karkoli obvezovalo. Brez dvoma njena kraljevska oblast priča o njeni veliki omikanosti, ne pa o duhovni grobosti. ${ }^{42}$ Artemizija je tudi izkušena v pomorskih bitkah, medtem ko so bile Amazonke na morju povsem neizkušene in jim je očitno samo $\mathrm{z}$ veliko sreče uspelo pristati na negostoljubnih krimskih tleh.

Ne smemo tudi pozabiti, da se, čeprav so v nekem smislu pod »moškim nadzorom«, vedejo pogumno. Ko se njihove zgodbe razvijajo, njihova dejanja postopoma prežema občutenje "modrosti«: Amazonke po eni strani prevzamejo vloge družinskih svetovalk, medtem ko njihovi mladi možje raje ubogajo. Po drugi strani se Artemizija izkaže za modro svetovalko in Kserksu ponudi izjemno priliko, da se izogne porazu. Ne glede na njihove namene je morda oboje doživelo širok odziv: kraljičin predlog v Faleru je presenetil in razdelil perzijske mogočnike. Hkrati so bili starši mladih Skitov začudeni nad odločitvijo svojih sinov, da se preselijo in požgejo mostove do bližnjih sorodnikov in tudi do svoje preteklosti. Glavna razlika je seveda ta, da Amazonkam njihovi tovariši nemudoma prisluhnejo - in to obrazloži izvor in nenavadnost njihovih potomk, Sarmatk - Artemizijin strateški načrt pa je na koncu zavržen, čeprav je pravilen.

Najopaznejša skupna poteza $\mathrm{v}$ teh dveh Herodotovih pripovedih pa je postopno spreminjanje prvotnih lastnosti protagonistk. Amazonke postanejo del nove »družbe«, novega okolja, ne da bi opustile nomadski način življenja. Kar se tiče Artemizije, se njen izvorni pogum umakne zvijačnosti, ko potopi zavezniško ladjo. Saj ne da bi jo krivili za nenadno izgubo sposobnosti, toda na koncu, ko je bilo njeno življenje ogroženo, ga je rešila $\mathrm{z}$ zvijačo, in ne $\mathrm{z}$ uporabo moči. In še zaključna opazka: Herodot je - kot vsi njegovi sodobniki dobro poznal mitološko izročilo o porazu Amazonk v Atiki; blizu Salamine bodo Atenčani spet premagali »naslednico Amazonk «, in to postane na koncu semiotična podobnost. 


\section{BIBLIOGRAFIJA}

Benardete, Seth. Herodotean Inquiries. Haag: St. Augustines Press, 1969.

Blok, Josine H. The Early Amazons. Modern and Ancient Perspectives on a Persistent Myth. Leiden: Brill, 1994.

Blundell, Susan. Women in Ancient Greece. Cambridge Massachusetts: Harvard University Press 1995.

Bowie, Angus M., ur. Herodotus: Histories Book VIII. Cambridge: Cambridge University Press, 2007.

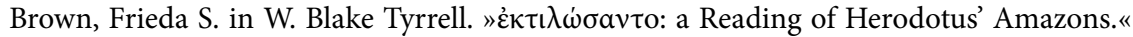
Classical Journal 80 (1985): 297-302.

Chiasson, Charles C. »Tragic Diction in Herodotus: some Possibilities.« Phoenix 36 (1982): 156-161.

Dewald, Carolyn. »Women and Culture in Herodotus' Histories. "V: Helene P. Foley, ur., Reflections of Women in Antiquity, 91-113. New York: Gordon \& Breach, 1981.

Flory, Stewart. The Archaic Smile of Herodotus. Detroit: Wayne State University Press, 1987. Flower, Michael. »Herodotus and Persia.« V: Carolyn Dewald in John Marincola, ur., The Cambridge Companion to Herodotus, 274-289. Cambridge: Cambridge University Press, 2006.

Hartog, François. The Mirror of Herodotus: the Representation of the Other in the Writing of History. Prevod Janet Lloyd. Berkeley: University of California Press, 1988.

Hazewindus, Minke W. When Women Interfere. Studies in the Role of Women in Herodotus' Histories. Leiden: Brill, 2004.

How, Walter W. in Joseph Wells. A Commentary on Herodotus, zv. I-II. Oxford: Oxford University Press, 1928.

Konstantakos, Ioannis M. »The Warlike and the Wary: The council of Xerxes in Hdt. VII 8-11 and some Near Eastern Tales. EIKASMOS 18 (2007): 219-244.

Lefkowitz, Mary R. Heroines and Hysterics. London: Palgrave Macmillan, 1981. Women in Greek Myth. Baltimore: John Hopkins University Press, 2007.

Masaracchia, Agostino. Erodoto. La battaglia di Salamina. Libro VIII delle Storie. Milano: Fondazione Lorenzo Valla, 1977.

Minns, Ellis H. Scythians and Greeks. A Survey of Ancient History and Archeology on the North Coast of the Euxine from the Danube to the Caucasus. Cambridge: Cambridge University Press, 1913.

Munson, Rosaria V. »Artemisia in Herodotus.« Classical Antiquity 7 (1988): 91-106.

—. Telling Wonders: Ethnographic and Political Discourse in the Work of Herodotus. Michigan: The University of Michigan Press, 2001.

Pomeroy, Sarah B. Godesses, Whores, Wives and Slaves Women in Classical Antiquity. London: Schocken, 1975.

Romm, James S. Herodotus. Yale: Yale University Press, 1998.

Rosellini, Michèle in Suzanne Saïd. »Usage de Femmes et autres Nomoi chez les 'Sauvages' d' Hérodote: Essai de Lecture Structurale. « Annali della Scuola Normale Superiore di Pisa 8, št. 3 (1978): 949-1005.

Rostovzeff, Mikhail Ivanovich. Iranians and Greeks in South Russia. Oxford: Clarendon Press, 1922.

Tyrrell, Blake W. Amazons. A Study in Athenian Mythmaking. Baltimore: John Hopkins University Press, 1984.

Vandiver, Elizabeth. Heroes in Herodotus. The Interaction of Myth and History. Frankfurt: Peter Lang, 1991. 